\title{
Radiodiagnóstico Ginecológico Mediante Neumoperitoneo
}

\author{
Doctor Marino Bafona Pinillos \\ Jefe de Trabajos Prácticos dé Raciodiagnóstico (por concurso) \\ Miembro del Centro Médico, Bogotá
}

El presente estudio comprende algunos exámenes radiológicos del aparato genital interno de la mujer, mediante el empleo de neumoperitoneo para delimitar el contorno externo de ellos. Este método de diagnóstico es conucido con A nombre de ginecografia simple, cuando sólo se emplea neumoperitoneo, y ginecografia completa cuando se agrega histerosalpingografia. Los exámenes fueron iniciados al conocer los trabajos efectuados por Stein en Chicago.

Los primeros casos eran enfermas que presentaban tumores abdominales " relrianos diagnosticados por otros exámenes de Rayos $\mathrm{X}$ o por el examen $\mathrm{f}$ -ico. Unicamente sc tenia la curiosidad de observar su aspecto al efectuar la ginecografia. Se penso igualmente que este método es de valor para delinear el - ntomo de las masas tumorales, y al mismo tiempo para indicar la posicion. amaño y aspecto de la cavidad uterina. Indudablemente esta informacion es de utilidad para el cirujano.

El neumoperitoneo pucde hacerse con aire, oxígeno o anhidrido carbonico. invectados por via trans-abdominal o con $\mathrm{CO} 2$ insuflado a través del cuello uterino. Unicamente hemos usado la via trans-abdominal porque nos ha parecido más practica y exenta de peligro. La vía trans-cervical, además de requerir estudio previo para cerciorarse de la permeabilidad tubaria, tiene el grave inconveniente del riesgo de producir embolia cuando se emplea oxígeno o aire que por esta causa están contraindicados por esa vía. En cambio la invección de estos gases lirectamente dentro de la cavidad abdominal, no tiene inconveniente. Es conocido el hecho que no es lo mismo inyectar gas dentro del tejido conjuntivo, muscular u otro cualquiera, que hacerlo dentro de la serosa peritoneal, dentro de ha pleura o en los espacios sub-aranóideos, donde el gas queda situado dentro de una cavidad cubierta por una membrana protectora. 
La punción de la pared la hemos hecho en el lado izquierdo, sobre el tímite externo del músculo recto, a la altura del ombligo o un poco por debajo. Generalmente hemos usado una aguja de punción lumbar No 20 de 3 pulgadas.

Al principio hicimos el neumo-peritoneo con anhídrido carbónico, pero después cambiamos a aire porque el anhidrido se absorbe muy rápidamente y no da tiempo a hacer observación radioscópica, que teniamos interes en realizar en los primeros casos, para buscar las provecciones más adecuadas de las masas tumorales que examinábamos. Elegimos como medio de contraste el aire porque puede ser inyectado en pequenas cantidades sucesivas, sin mavor absorción entre cada invección. De esta manera se llega al neumo-peritoneo adecuado, por distención gradual de la pared abdominal, sin grandes molestias, sobre todo en enfermas que deben permanecer en cama, como eran las pacientes elegidas.

El neumoperitoneo sucesivo con aire se practicó invectando más o menos 400 c.c. el primer día, 600 el tercer día y alrededor de 1.000 el quinto o sexto día, como tiempo previo al examen radiologico. La cantidad de gas se mide y la cámara de neumoperitoneo se calcula suficiente de acuerdo con los datos dados por la cantidad invectada y por timpanismo y grado de distencion de la pared abdominal en cada caso. Por termino medio deben invectarse entre 1.500 y 2.000 c.c. de gas según el tamaño del abdomen y de la masa tumoral que va a ser examinada.

Posteriormente hemos vuelto a usar $\mathrm{CO}_{2}$, que es sin duda mejor medio de contraste que el aire porque su absorción rápida no causa molestias después de la insuflación, y porque no hay peligro de producir embolia. Es el medio de elección sobre todo en los casos que solamente se necesita hacer ginecografia simple. La desventaja radica en la rapidez con que deben efectuarse las radiografias antes de que se absorba gran parte del gas, pues 5 minutos después de la inveccion va es notoria la disminución del tamaño de la cámara de neumoperitoneo que se hace inadecuada. Cuando se emplea CO2 y se desea hacer una ginecografia completa, hay que proceder a hacer primero la histerosalpingografia y después el neumoperitoneo.

Para tal efecto, una vez invectada la matriz y las trompas con el medio opaco, al hacer la insuflación peritoneal se coloca la mesa en Trendelemburg para facilitar el ascenso del gas, que debe ser invectado en este caso, de una sola vez en la cantidad requerida. Rápidamente, sin volver la mesa a la posicion horizontal, se coloca la paciente en posición genu-pectoral parcial y se toman las placas sin pérdida de tiempo. Igual procedimiento hemos seguido al hacer la ginecografia simple con $\mathrm{CO}$, para tomar las placas lo mas rápidamente posible.

La enferma debe ser preparada con una inveccion de morfina una media hora antes del examen, porque la distencion brusca de la cavidad abdominal producida por el neumoperitoneo, es bastante dolorosa y hace muy incómodo el examen. Es requisito indispensable la preparación con anterioridad mediante enema de limpieza rectal. La vejiga debe ser evacuada inmediatamente antes del examen, ya sea por micción, o mejor mediante cateterismo. 
Respecto a la manera de dirigir el examen radiológico y a las condiciones de su interpretación, hacemos notar los siguientes hechos: a) La posición genupectoral parcial ideada por Peterson y divulgada principalmente por Stein, es la más adecuada y eficiente para esta clase de exámenes; da informacićn de alteraciones y de anomalias muy pequeñas, que no se pueden identificar en otras proyecciones. b) Los tumeres encarcelados dentro de la pequeña pelvis, impiden la neumatización de los fondos de saco, e imposibilita la producción de imágenes suficientemente contrastadas. Igual cosa sucede con las lesiones inflamatorias que han producido adherencias extensas de la cavidad pelviana. c) Debe tenerse en cuenta la presencia de asas intestinales no desplazadas, que de vez en cuando pueden simular imágenes de quistes. Estas pseudo-imágenes se diferencian por el cambio de aspecto si se toman varias placas, y por ausencia de pedícuio que las una al anexo correspondiente. $d$ El desplazamiento exagerado de los tumores o de los órganos a ellos adheridos hacia arriba del abdomen debido a su peso o a otra causa, los coloca fuera del campo de la proyección genu-pectoral o da imógenes inadecuadas para el diagnostico. En caso de lesiones grandes desplazadas por encima del estrecho superior, deben tomarse radiografías en Trendelemburg en posiciones oblicuas, laterales o antero-posteriores según el caso.

La posición genu-pectoral parcial la hemos hecho en mesas de Rayos X de tipo corriente, Fig. 1. La paciente puesta primero en decúbito ventral debe en seguida flexionar moderamente los muslos, apovando en la mesa las rodillas, c] pecho y la cabeza. Debe arquear cuanto sea posible la columna lumbar exagerando la lordosis. Generalmente hemos colocado un balón de compresión abciominal inflado moderadamente debajo del pubis; esto da mayor estabilidad $\mathrm{y}$ comodidad y al mismo tiempo sirve de compresion. El tubo de Rayos X, puesto un proyección vertical, se centra sobre la punta del sacro a 36 ó 40 pulgadas de lis placa.

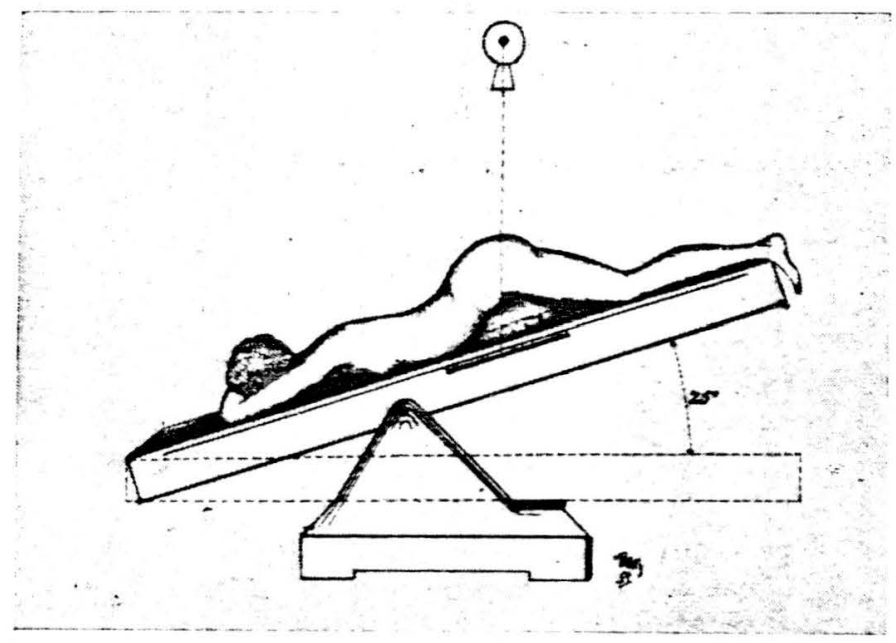


Para provocar el ascenso del gas se golpea con cierta suavidad la región lumbo-sacra con el puño de la mano. La cámara de neumoperitoneo que llena entonces la cavidad de la pelvis, hace que las vísceras abdominales se desplacen por gravedad hacia la parte alta del abdomen, en cambio los órgnos genitales quedan suspendidos por los ligamentos.

La radiografía tomada en esta proyección, Fig. 2, muestra: la vejiga evacuada, que aparece en forma de un óvalo sobre la cara posterior del pubis. La pared anterior del abdomen sobreproyectada a la vejiga. El utero visto sobre su ejc longitudinal, está situado detrás de la vejiga, separado de ella por el fondo de saco vésico-uterino, que puede ser más o menos amplio según la inclinación que se dé a la mesa o el grado de movilidad que tenga el mismo útero. Se observa el fondo de saco de Douglas, con la porción más alta, donde el peritoneo pasa sobre la cara posterior del útero. El recto evacuado se proyecta sobre la cara anterior del sacro. Los anexos aparecen a cada lado, siendo especialmente visibles los ovarios, las trompas, el ligamento ancho y el ligamento redondo. El tamaño de los organos se aumenta debido a la distancia que los separa de la placa.

Las radiografías siguientes muestran algunos aspectos de las diferentes imágenes encontradas en ginecografia simple.

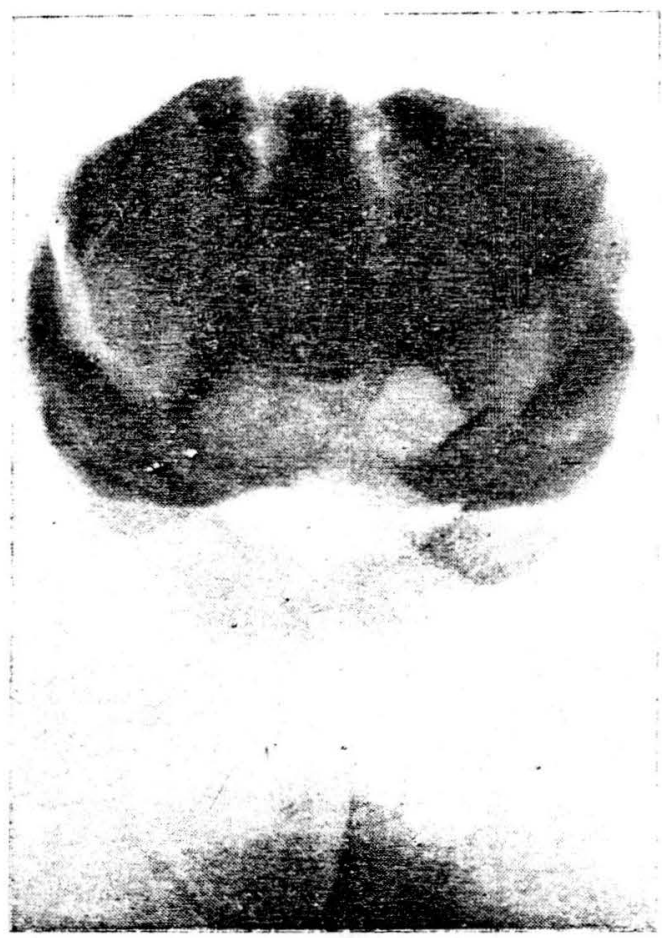


Fig. 3: En esta enferma contrasta el tamaño de los ovarios, que son simétricamente grandes y densos, con la matriz relativamente hipoplástica, es el cuadro radiológico de los ovarios escleroquísticos.

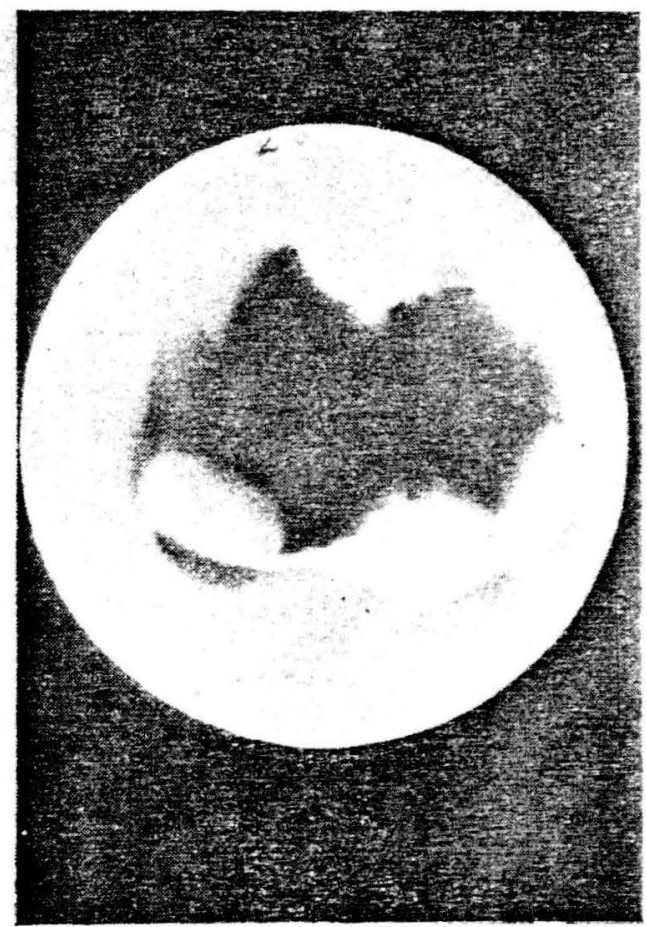

FIG. 3

Ovarios escleroquisticos.

Fig. 4: Por el contrario en esta radiografia el útero está aumentado de tamaño y el ovario derecho muy aumentado de tamaño, presenta forma quística,

FIG. 4

Quiste luteinico del ovario derecho acompanado del correspondiente aumento de tamaño de la matriz. Deformación en rosario de la trompa izquierda. 
límites curvilíneos bien definidos y transparencia homogénea. Es la imagen que se encuentra en los casos de quiste luteínico. Los quistes chocolate, en contraposicićn, presentan límites poco netos debido a que se adhieren frecuentemente y además la densidad no es uniforme. Hacemos notar que el ovario izquierdo es normal pero la trompa izquierda muestra contorno externo irregular, en ro sario y se provecta ligeramente enrollada. Esta paciente tenía una T.B.C. pulmonar activa.

Fig. 5: En contraste con los casos anteriores, en esta enferma virgen, sin menarquia a los 24 años, se tuvo la sospecha clínica de ausencia de los ovarios. La demostración, mediante la ginecografía, de presencia de ovarios aunque fue-

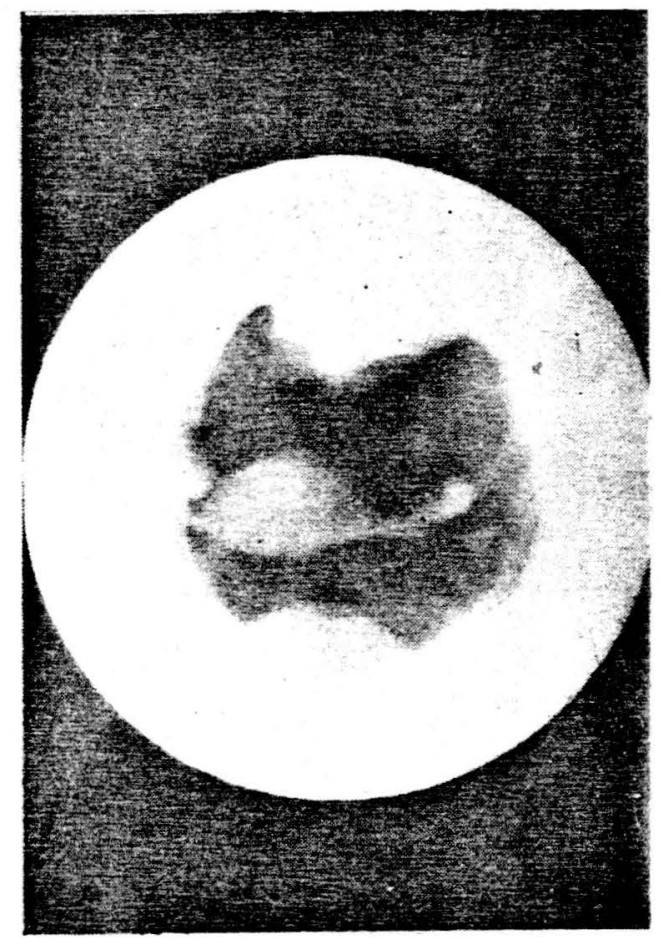

FIG. 5

Ovarios hipoplásicos. Utero infantil.

ran de tamano muy pequeño. y de matriz de tipo infantil, decidió al médico a insistir en el tratamiento hormonoterápico y poco después se obtuvo la primera menstruacion.

Es notorio como la ginecografia da información de alteraciones morfológicas muy pequeñas, como es por ejemplo el tamaño de los ovarios. Además permite diférenciar, en muchos casos con gran precisión, los elementos constitutivos de cada anexo, como es el caso de la Fig. 10, donde se destacan dentro de la imagen del ligamento ancho izquierdo, la trompa, el ligamento útero-ovárico, el ovario y hacia adelante el ligamento redondo. 
Fig. 6: La ginecografía sencilla en esta enferma mostró dos imágenes de dientes en el lado derecho de la cavidad pelviana, acompañados de una zona de densidad calcárea amorfa, proyectados dentro de la imagen de un quiste, que a su vez muestra zonas de menor densidad, producidas por la presencia de tejido adiposo. Esta es la imagen de los quistes dermoides.

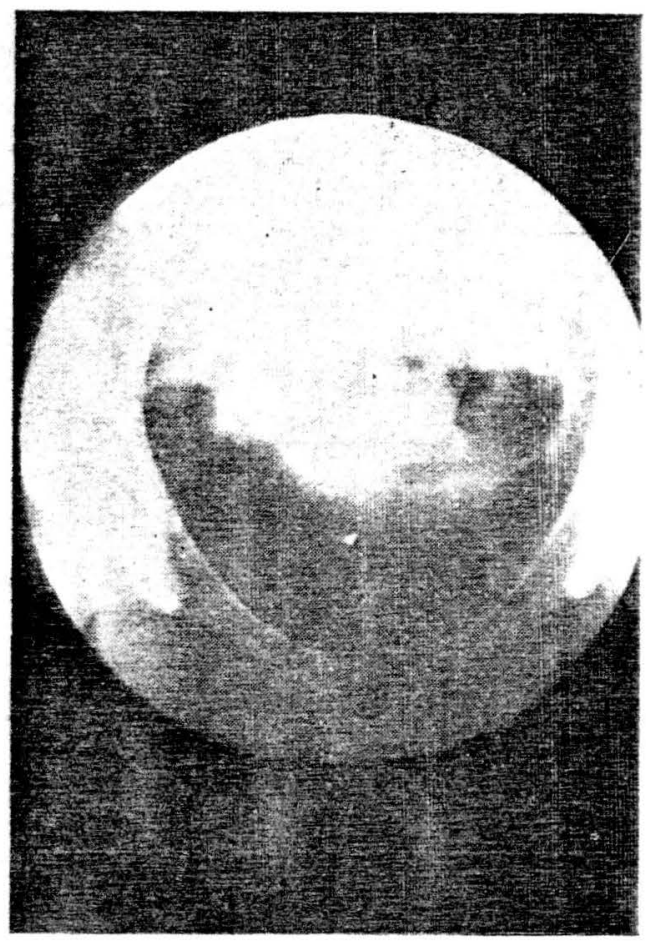

FIG. 6

Quiste dermoide derecho: presencia de dientes y zona de calcificación amorfa dentro del quiste. Además se aprecia tejido adiposo de escasa densidad.

Fig. 7: En otra radiografía de la enferma anterior, además del quiste mencionado, apareció otra imagen redondeada de escasa densidad que se provecta whe la cara anterior del sacro. Esta última, no determinada en la placa anterior es una imagen de pseudo-quiste, producida por una asa intestinal no desplazada como fue confirmado en la operación, donde solamente se encontró un quiste. El diagnostico de estos pseudo-quistes es fácil si se tiene en cuenta que frecuente- 
mente contienen gas, la no persistencia de ellos en varias placas, o el cambio de su aspecto, así como también la falta de pedículo inferior o lateral que los una a! ovario respectivo.

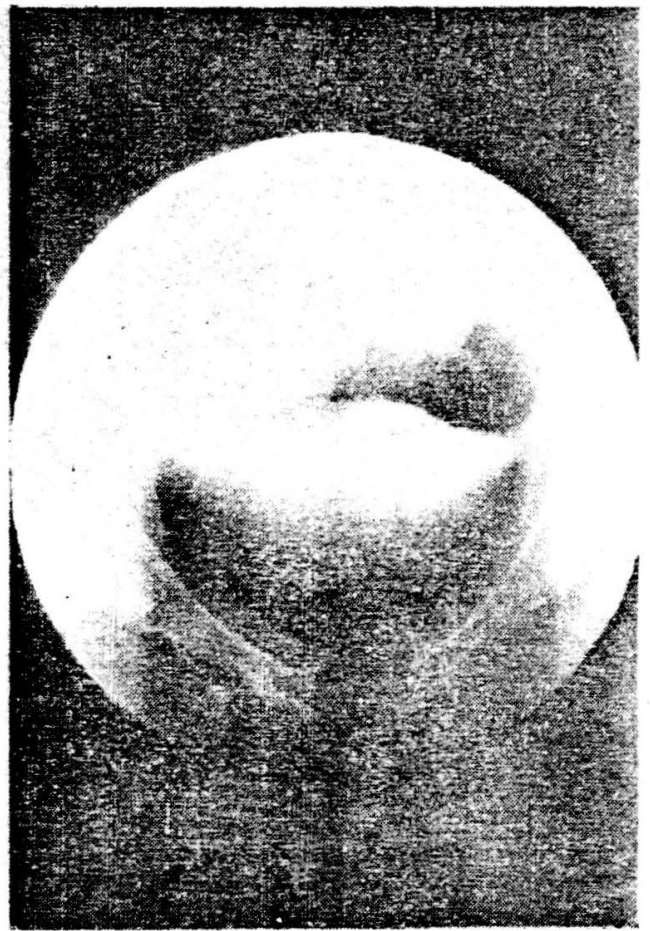

'FIG. i

Otra radiografia del caso anterior: imagen de pseudo-quiste. Se nota mejor el tejido adiposo del quiste dermoide.

Fig. 8: Esta enferma padecía de TBC. genital comprobada por biópsia del endometrio. La ginecografía mostró falta de neumatizacion, adherencias extersas del lado derecho de la cavidad pelviana y retracción del ligamento izquierdo que habia producido desviación del útero hacia este lado. Se observaron varias zonas de densidad calcárea tanto en el anexo izquierdo como en el lado derecho sobre la zona densa mencionada. La vejiga se evacuo por cateterismo para apreciar me jor las zonas adheridas, que tienen importancia en el diagnóstico de TBC. genital junto a la presencia de calcificaciones y a la alteracion morfologica de las trompas. Dicha alteración consiste en retracción de ellas por adherencias y en irre- 
gularidad de su calibre externo, que da al examen ginecográfico el aspecto de trompás en rosario. La histerosalpingografía comprueba alteracićn del aspecto de la mucosa, con sectores en que hay estenosis del conducto.

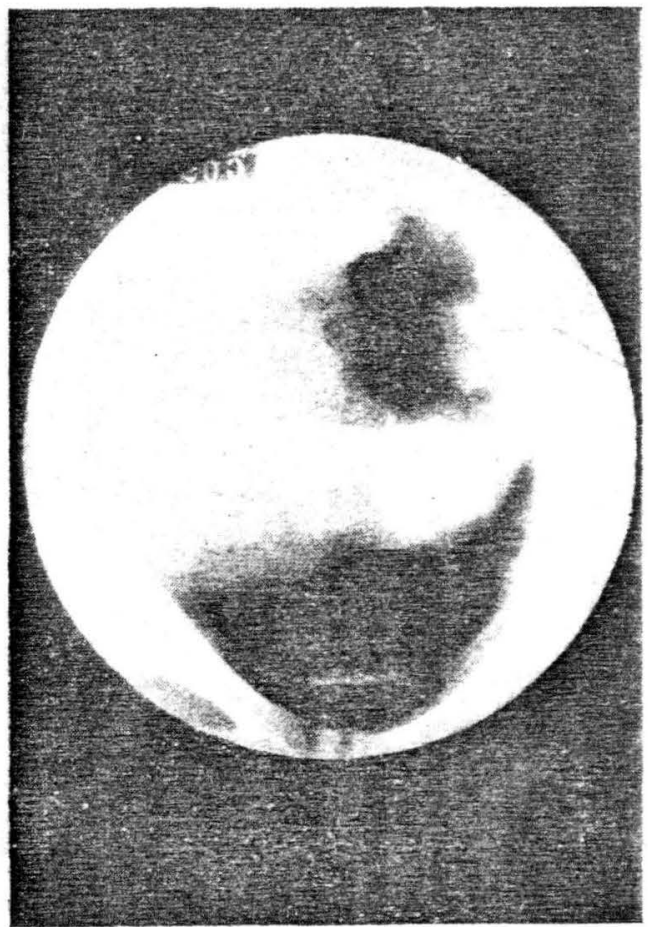

FIG 8

Adherencias extensas y calcificaciones producidas por TBC. genital. Utero traccionado hacia el lado izquierdo.

Fig. 9: El aspecto descrito anteriormente st observa con mavor claridad en esta radiografía que presenta deformación en rosario del extremo distal de la trompa derecha, sobreproyectada al ovario. I retrascion de la trompa izquierda

Fig. 10: La permeabilidad y conformacion normal de los fondos de saco peritoneales, especialmente del fondo de saco de Douglas y de la cavidad pelviana en general, es un dato importante suministrado por la ginecografía. Para evitar confuciones y para hacer resaltar bien la neumatizacion debe evacuarse completamente la vejiga. La Fig. 10 corresponde a una vejiga parcialmente evacuada que provoca alteración de la imagen del Douglas y ha producido rechazo 


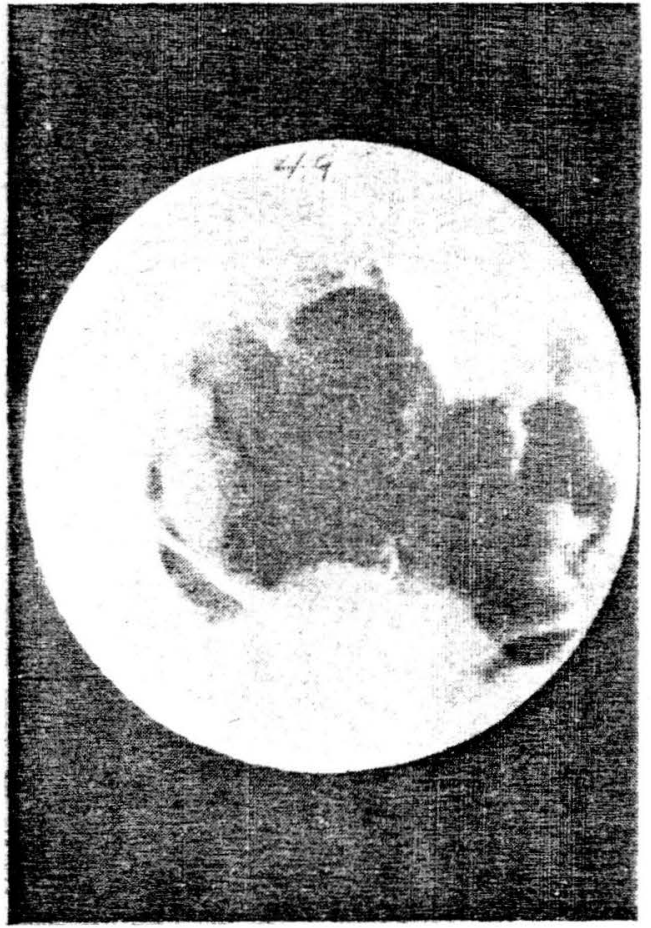

FIG. 9

Imagen en rosario de ambas trompas. Retracción de la trompa izquierda. Evacuación parcial de la vejiga que altera la imagen de neumatización del Douglas.

FIG, 10

Evacuación parcial de la vejiga que altera la imagen de neumatización del Douglas

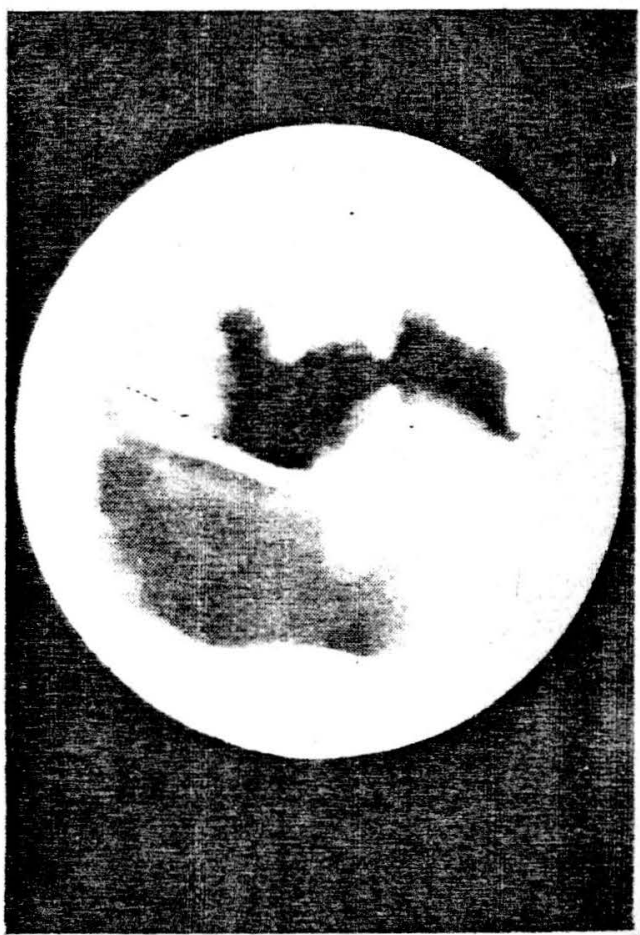


del útero hacia atrás. La Fig. 11 muestra una vejiga llena, proyectada dentro del contorno del extremo superior de la pelvis y delimitada por gas en su mitad superior.

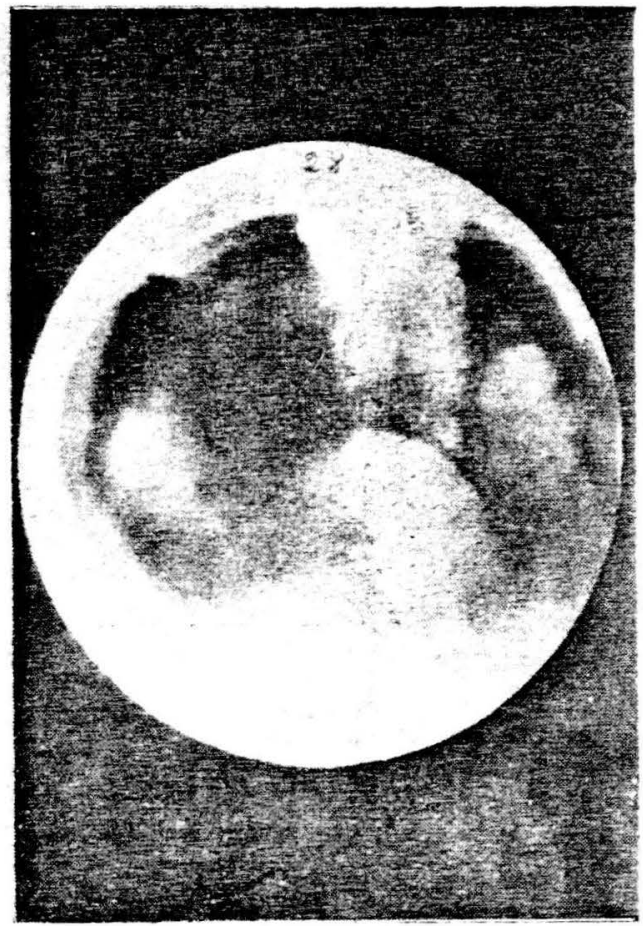

FIG. 11

Vejiga no evacuada proyectada sobre el contorno del estrecho superior de la pelvis.

Fig. 12: Los abortos al cuarto o quinto mes de la gestación, repetidos en inco veasiones hicieron pensar en la presencia de alguna causa mecánica en cste caso, a pesar de que el examen ginecologico hecho en diferentes ocasiones $\checkmark$ por diferentes especialistas fue siempre negativo. La histerosalpingografia, Fig. 13 muestra una imagen de compresion en el istmo, que se explica claramente al examinar la ginecografia sencilla Fig. It, donde resalta una eminencia en la cara posterior del útero que era debida a la presencia de un fibromioma situado en esa región. En el anexo izquierdo se provectan dos imágenes redondeadas que corresponden a la presencia de un quiste de la trompa y al ovario izquierdo. La ginecografía completa no aclaro exactamente la situación de la imagen del quiste, pero sí hizo resaltar mejor la presencia del tumor de la pared posterior del útero. La falta de neumatización del lado derecho de la pelvis ura debida a adherencias peritoneales producidas por una apendicitis aguda opeiada anteriormente. En la intervencion quirúrgica se comprobó un fibromioma en la pared posterior del istmo uterino y se demostró un quiste de la trompa izouierda 
FIG. 12

Histero-salpingorafia; imagen de compresión de la substancia opaca en istmo uterino.
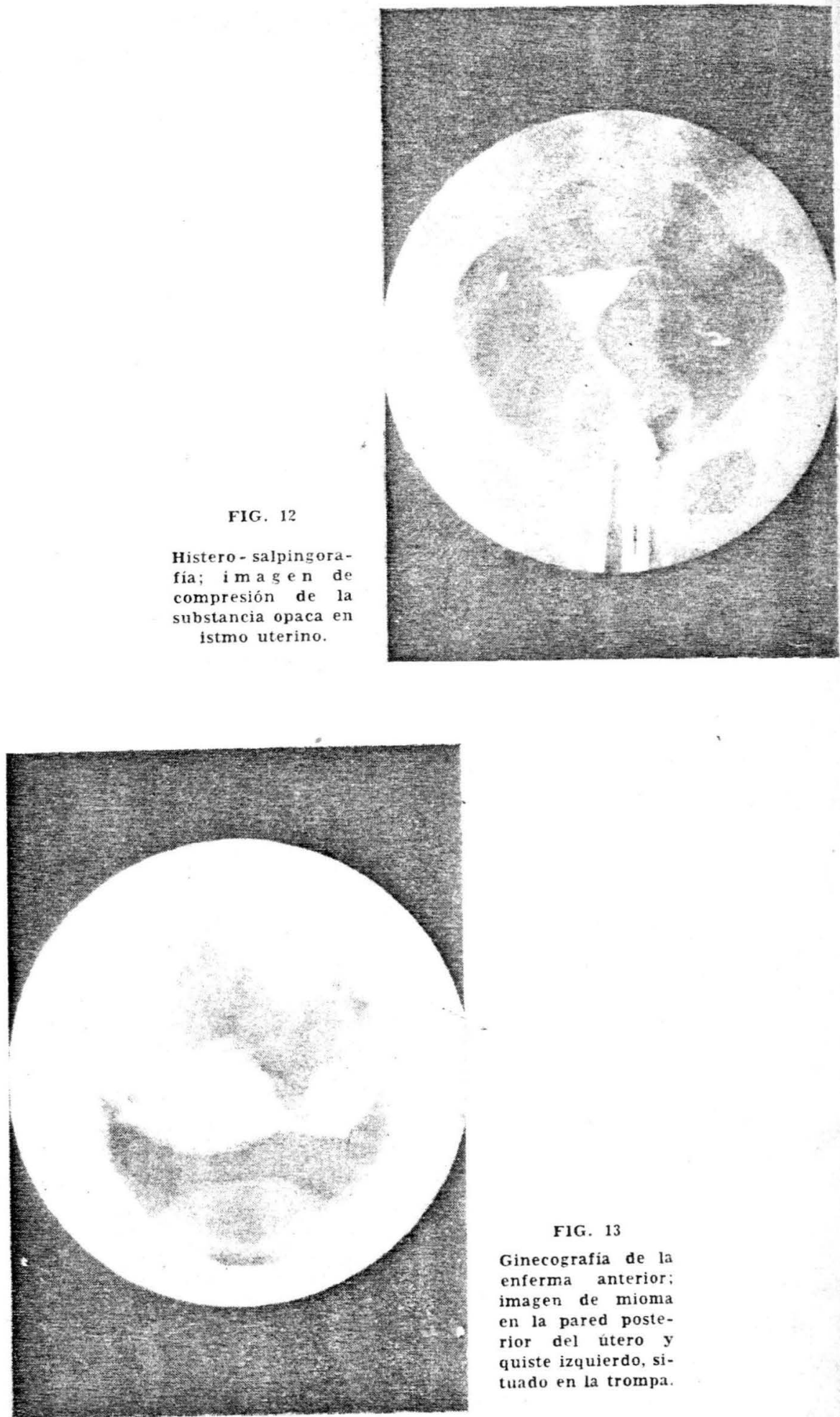

FIG. 13

Ginecografia de la enferma anterior: imagen de mioma en la pared posterior del útero y quiste izquierdo, situado en la trompa. 


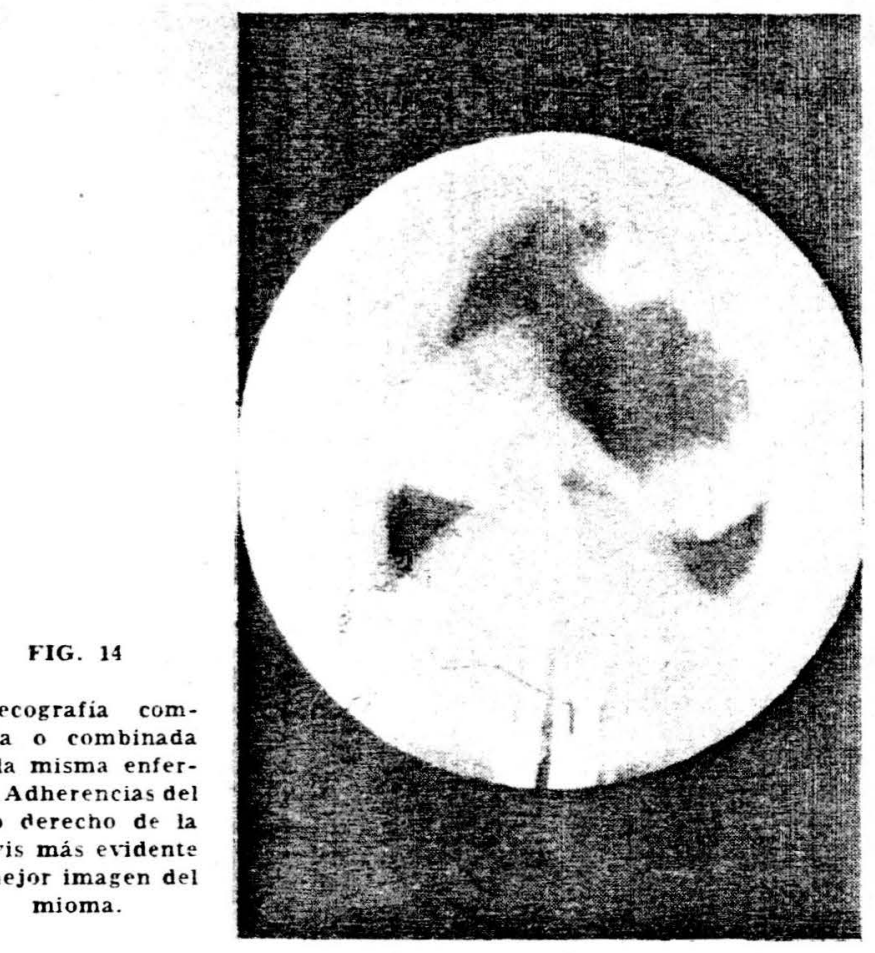

Ginecografia completa o combinada de la misma enferma. Adherencias del lado derecho de la pelvis más evidente y mejor imagen del mioma.

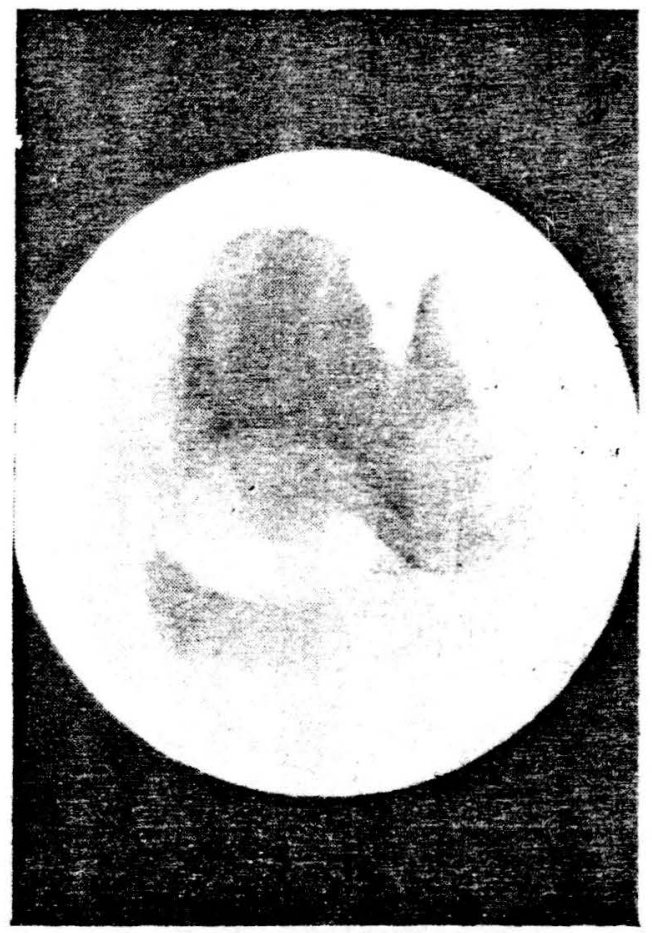

FIG. 15

Radiografia del caso a terior. No muestra la alteración de la pared posterior del útero, debido a la proyección. Hay aumento del tamaño de la imagen de quiste ixquierdo. 
provección oblicua, en Trendelemburg. Fig. 19, cambia completamente la imagen siendo facil el diagnéstico de fibromioma desarrollado a expensas del fondo y de la pared posterior de la matriz. Fácilmente se comprende pues la importan cia de practicar el examen in Trendelemburg y en posiciones laterales u oblicuas de la paciente

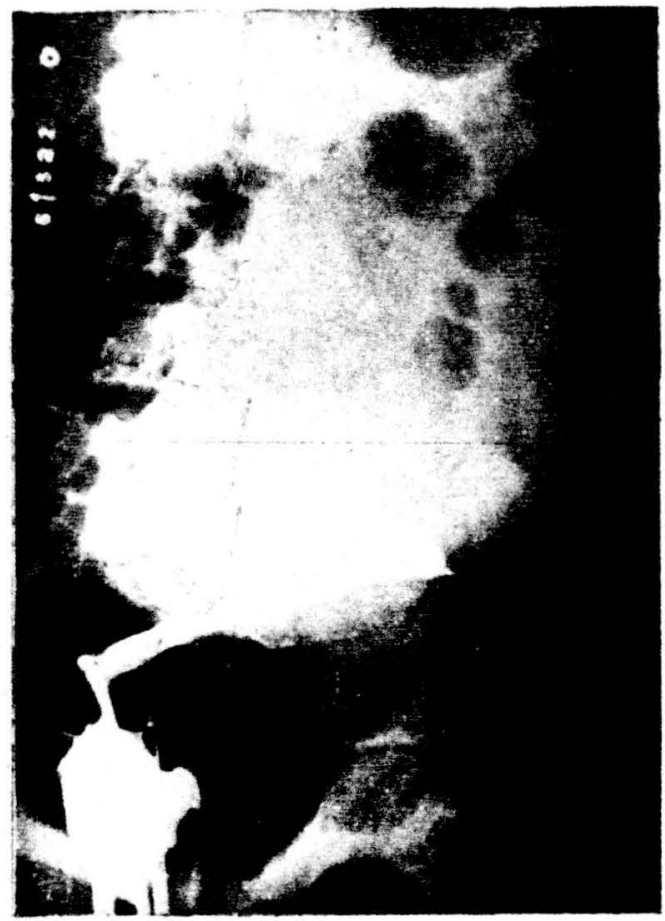

FIG. 19

Proyección oblicua del caso anterior. Fibromioma desa. rrollado sobre el fondo y pared pos. terior de ùtere.

Fig. 20: El neumoperitoneo muestra en este caso alyunas eminencias en d contorno inferior de una masa grande, redondeada que en conjunto da la im presion de un fibromioma. Sin cmbargo, las placas tomadas después de histero silpingegrafia con inclinacion de la mesia hacia la cabeza, han producido la di. sociacion o separacion de la matriz y de la masa tumoral, que es un quiste del ovario, lacilitando as al diagnóstico.

Fig. 21: In ese examen se ha delimitado el contorno inlerior nitido y cur vilíneo de una gran masa tumoral de limites regulares, yue se provecta por en cima de la cavidad uterina la cual ha sido traccionada hacia arriba. La trompa derecha muy alargada, sigue el contorno de la masa tumoral. Este aspecto radio lógico es el de un yusse del ovario.

Fig. 22: In el presente case fue imposible desplazar la masa tumoral de la cavidad de la pelvis al inclinar la mesa de examen. La provección gena pectoral no dio ninguna imagen debido a la falta de neumatización de la cavi dad pelviana. La inyección de medio opaco delimitio un mioma sub mucoso gran 


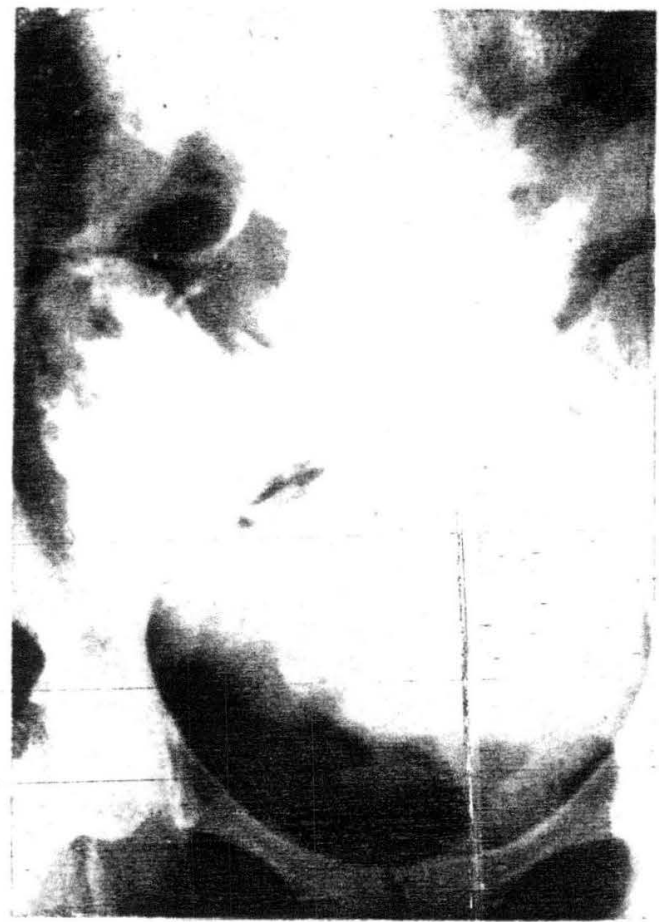

FIG. 20

Hay varias eminencias en el contorno inferior de una $\mathrm{ma}$. sa tumoral, sin qua se pueda observar si hay utero normal sobreproyectado al tumor.

FIG. $20 \mathrm{~b} / \mathrm{s}$

Disociacion de la imagen del tumor y de la matriz, al au mentar la inclina clón de la mesa.

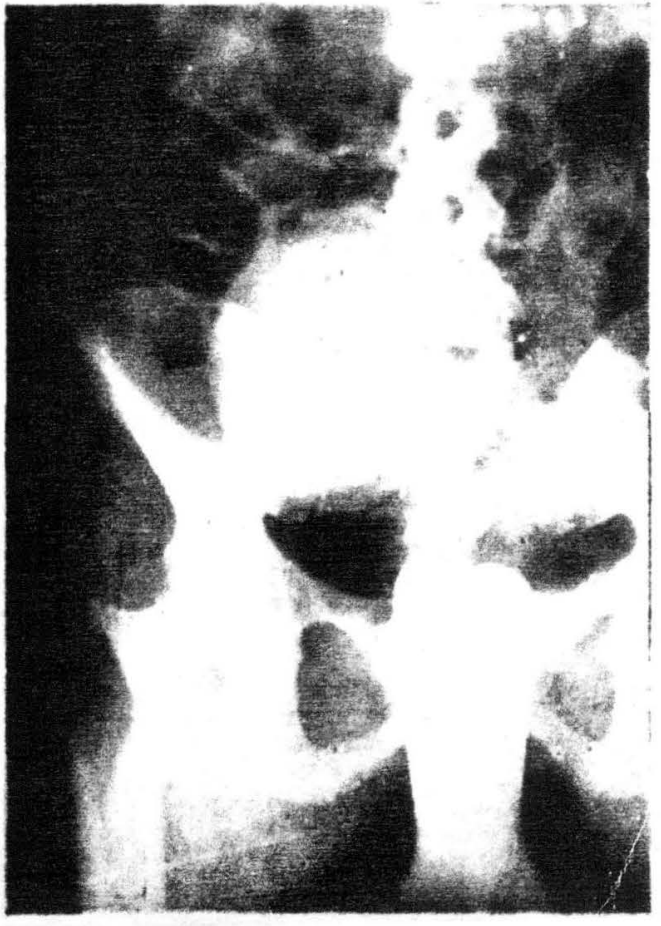




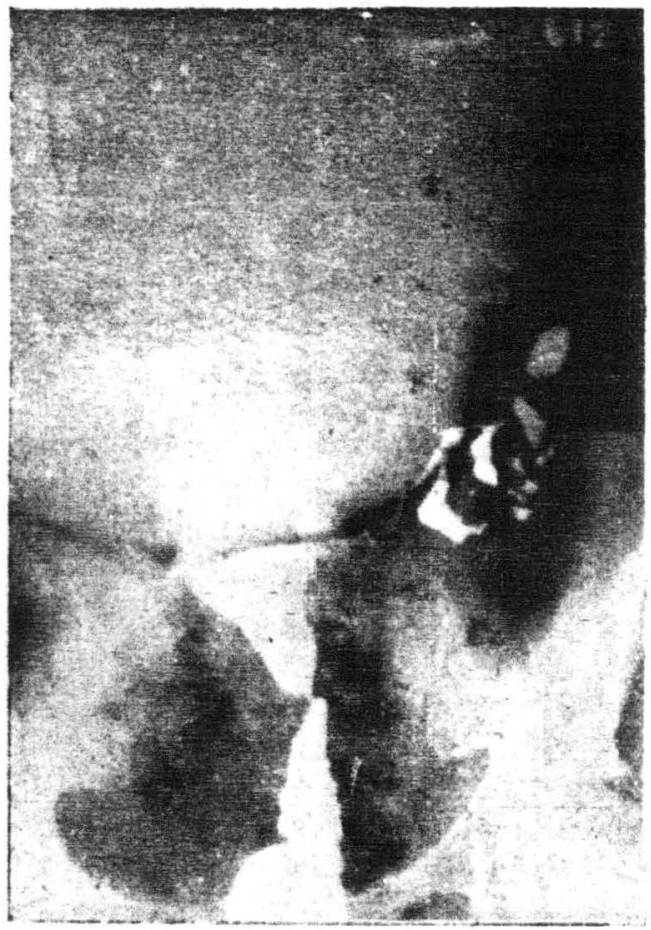

FIG, 21

Aspecto caracteristico ife un quiste gigante del ovario. $C$ a $v$ i d a d uterina normal, traccionada hacia arriba.

FIG. ?2.

Mioma submucoso proyectado dentro de una masa tumoral esférica. La escasa de medio opa. co dellmita bien el tumor nubmucoso. FIG. 24

Gran tumer denso $y$ esférico, de contornos muy requla. res.

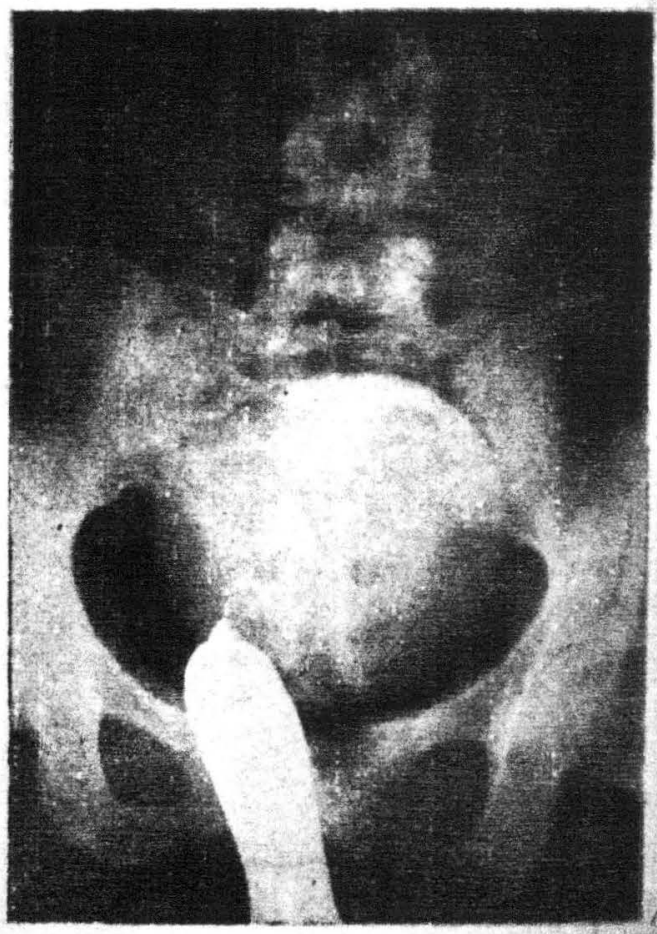


de de contornos regulares situado en el istmo. El fondo de la cavidad uterina está ensanchado y concavo. El contorno del tumor presenta varias eminencias características de fibromioma, que unidas a la presencia de un mioma sub-mu cose y a la falta de discriacion de la imagen del tumor y de la cavidad uterina. y mioma uerino comprobado en la operación.

Dehe anotar que la delimitacion del mioma sub-mucoso es mas evidente in l. placa hecha con casisal inveccion de medio opaco que en las otras, en que 1) Henamiente más complete y la distención de la cavidad, solamente demues 11.m lis lesiones situadas en el contorno de ella. Fig 23. Para evitar la presencia de imágenes de falta de llenamiento del medio opaco producidas por gas, conviene purgar de aire el tubo de conducción y la cánula, antes de colocar ésta en al cuello uterino.

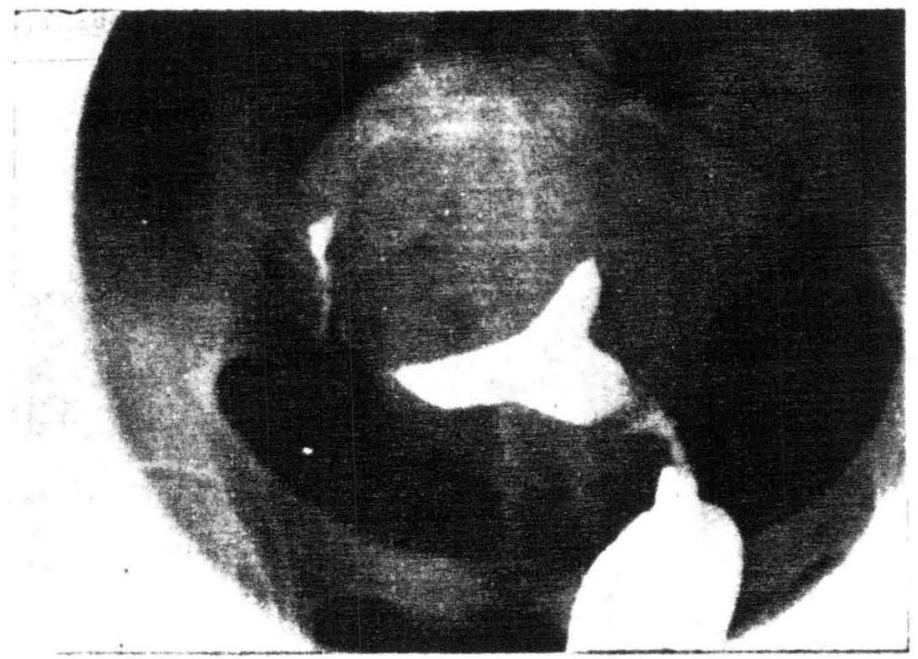

FIG. 23

Radiografia de la enferma anterior con más Uenamien. to de la cavidad uterina: el fondo aparere cóncavo $y$ se detimita menos el mioma del istmo. No hay disociación de las imágenes (tumor y cavidad uterina) en posicion de Trendelemburg.

Figs. 24 y 25: En estas dos radiogralias contrastan los limites regulares del antorno externo del útero mus aumentado de tamaño, $y$ los defectos de llena micnto de la substancia opaca en la cavidad uterina; estos fultimos simulan at zucuso modo el aspecto de los carcinomas gástricos. El conjunto de la imagen hilure de los fibromiomas uterinos; la cavidad de éstos generalmente agrandadi, une contornos lisos y defectos de llenamiento de limites regulares. El examen witumopatoligico del caso anterior comprobo la presencia de fibrosarcomi utcrino.

Figs. 26 y 27: Estas placas muestran el aspecto tipico de grandes fibromio mas uterinos cón aumento de tamaño de la cavidad, presencia de miomas sub 


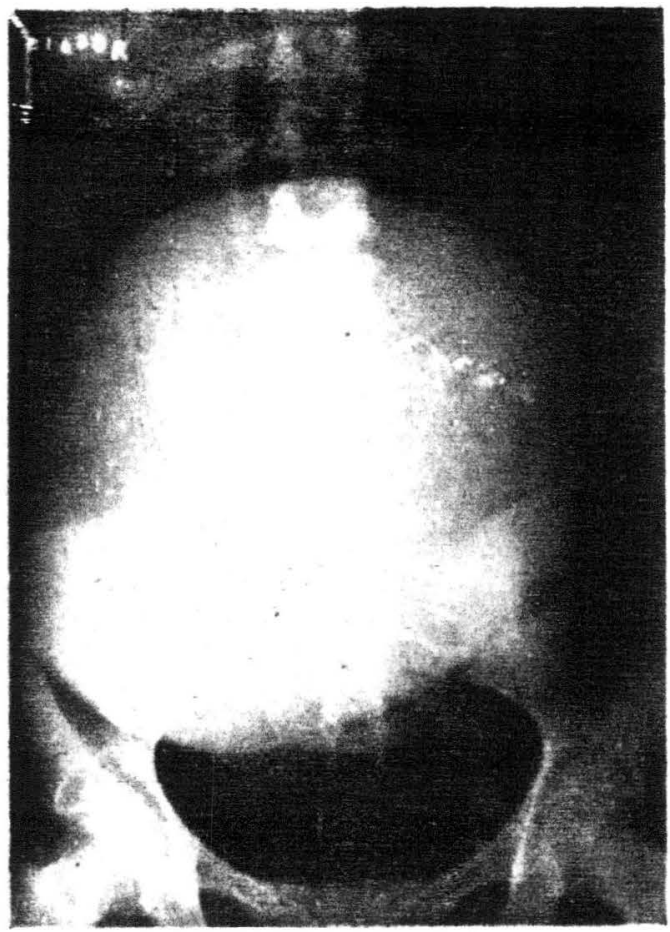

FIG. 24

Gran tumor denso y esférico, de contornos muy regulares.

FIG. 25

Defecto de llenamiento del medio opaco de contornos irregulares, con estenosis de la cavidad.

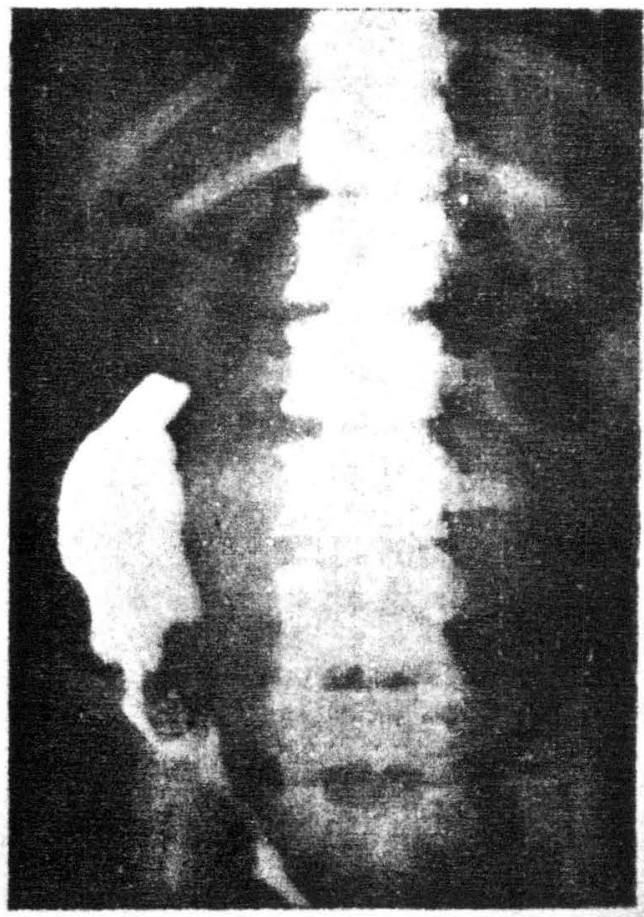




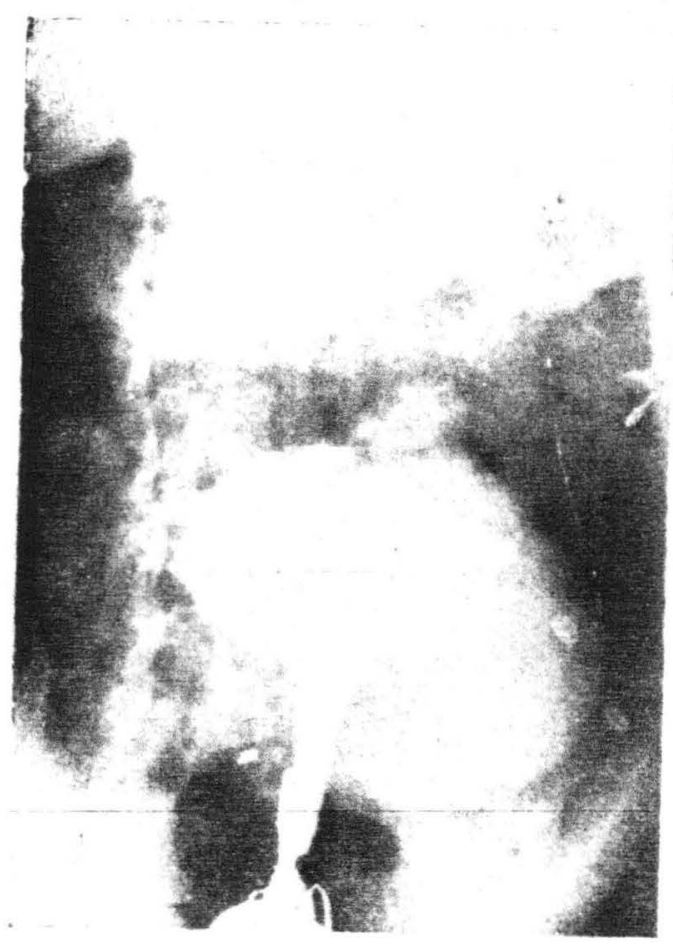

FIG. 26

Fibromioma uterino.. Contorno lobulado del $t u m o r$. Miom: submucoso en el cuerno derecho d ela cavidad del utero.

FIG. ?2

tibromioma del utero. La cavidad esta agrandada, es de contornos regulares.

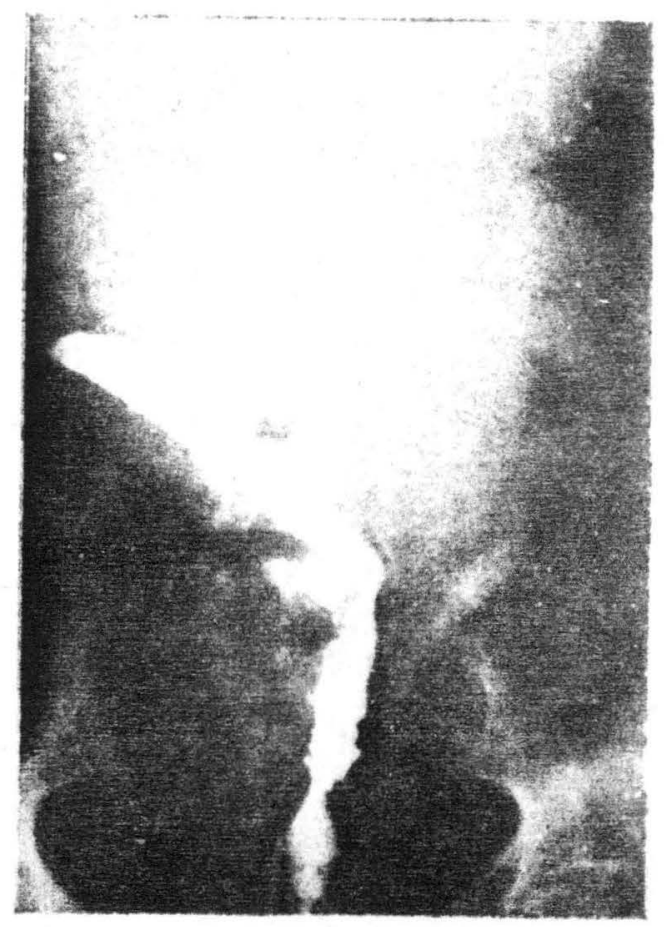


mucosos y contornos lobulados de las masas tumorales que se han delimitado mediante neumoperitoneo.

En resumen, la ginecografía es el método de examen radiológico de los ór ganos genitales internos de la mujer, delimitados mediante el empleo de neu moperitenco. Este se hace preferentemente con anhidrido carbinico, el cual so absorbe rápidamente, evita las molestias dolorosas después de la inveceion y no tiene peligro de producir embolia. La via más práctica para insectar la gran can tidad de gas indispensable es la transabdominal, pues no requiere estudio previo de la permeabilidad tubaria. La proyeceion genu pectoral parcial, ideada por $\mathrm{Pe}$ terson hace ya muchos años, es la más adecuada para el diagnóstico de alteraciones morfológicas pequeñas de los órganos internos femeninos que no aparecen en ninguna otra provección. Con ella se consigue no solamente delimitar estos organos sino también los fondos de saco peritoneales y la cavidad pelviana. Da información de la presencia de adherencias que tabiquen la pelvis, hecho de gran importancia tanto para el diagnóstico ginecologico en general, como en los casos de esterilidad. La prueba de Rubin positiva indica la penetración de gas en la cavidad abdominal, sin decir nada respecto de si los ovarios se encuentran libres a aislados con adherencias. La informacion eficiente que da la proyección genu-pectoral se comprueba en este trabajo con varias radiografias, a las que se han agregado otras proyecciones de utilidad en tumores grandes desplazados fucra del campo de la provección genu-pectoral.

Damos sinceros agradecimientos a los Dres. Pablo Cromez Martine,z Issa Sabbag. Arturo Aparicio, Jaramillo, Rodulio Camero y Ciuillermo Loper Es cobar por la eficiente colaboración y estímulo en el presente trabajo.

\section{B I B L I O G R A F I A}

"Gynecography in the diagnosis of ovarian disorders", Irving F. Stein.

"Progress in Clinical Endocrinology", January, 1950

"A table for Gynecography", Irving F. Stein and Robert A. Arens. American Journal of Obstetrics and Ginecology. May 1952, Vol. 63, No 5.

"Office Gynecoiogy". J. P. Greenhill. Fourth Edition. 